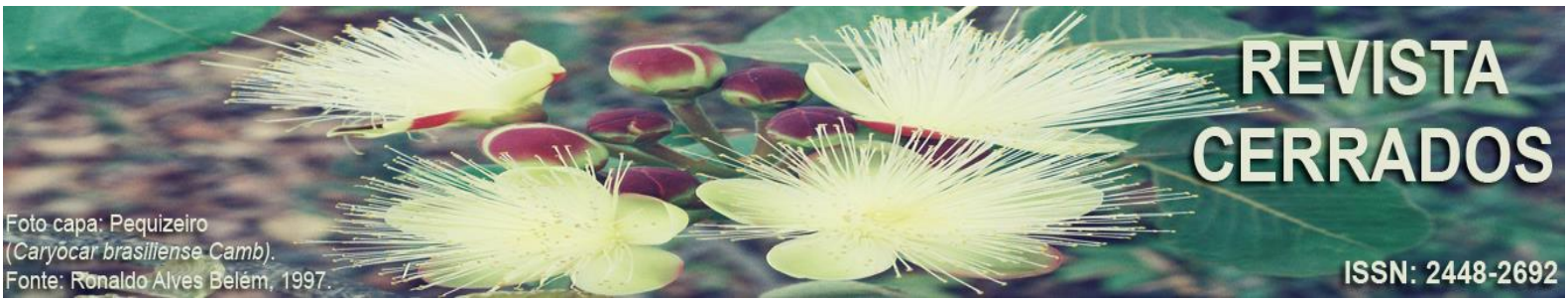

\title{
A CANA-DE-AÇÚCAR NO MUNICÍPIO DE CAPINÓPOLIS (MG) E O (RE)ORDENAMENTO SOCIOTERRITORIAL
}

\section{THE SUGARCANE IN THE MUNICIPALITY OF CAPINÓPOLIS (MG) AND THE SOCIO-TERRITORIAL (RE)ARRANGEMENT}

\section{LA CAÑA DE AZÚCAR EN EL MUNICIPIO DE CAPINÓPOLIS (MG) Y EL (RE)ORDENAMIENTO SOCIOTERRITORIAL}

\author{
Luiz Carlos Santos da Silva \\ Universidade Federal de Goiás - UFG \\ e-mail: <luizgeo28@gmail.com>. \\ Estevane de Paula Pontes Mendes \\ Universidade Federal de Goiás - UFG \\ e-mail: <estevaneufg@gmail.com>.
}

\begin{abstract}
Resumo
O presente artigo é parte dos resultados da dissertação de mestrado e tem como objetivo compreender as transformações socioespaciais no município de Capinópolis (MG) decorrentes da territorialização da agroindústria canavieira Vale do Paranaíba. Assim, buscamos entender os efeitos sociais na vida dos trabalhadores que migraram da região Nordeste do país ao município de Capinópolis (MG) para a atividade do corte de cana. A metodologia constitui-se pela revisão teórica dos autores que discutem a temática da cana-deaçúcar e a migração, bem como pela pesquisa documental, por meio de sites do IBGE, da SIAMIG e da Prefeitura de Capinópolis (MG), e pela pesquisa de campo, que nos deu a dimensão do problema aqui levantado. Em seguida, foram feitas as tabulações dos dados da pesquisa, os quais foram transformados em gráficos e fotos. Percebemos que dezenas de trabalhadores perderam seus empregos e foram obrigados a desempenhar outras atividades para poderem sobreviver.
\end{abstract}

Palavras-chave: Capinópolis (MG); Agroindústria canavieira; Migração. Crise. 


\begin{abstract}
This article is part of the dissertation results and aims to understand the transformations socioespaciais in the municipality of Capinópolis (MG) due to the territorialisation of the sugarcane agroindustry Vale do Paranaíba. In this order, we want to understand the social effects on the lives of workers who migrate in the Northeast region of the country to the municipality of Capinópolis (MG) to the activity of cane cutting. The methodology was based on theoretical review of the authors that discuss the subject of sugarcane and migration, in addition to the documentary search through websites of IBGE, SIAMIG, Capinópolis (MG) and the field research that gave us the scale of the issue here raised. Then, tabs were made of the research data and turned into charts, tables and pictures. We realize that dozens of workers have lost their jobs and were forced to carry out other activities in order to survive.
\end{abstract}

Keywords: Capinópolis (MG); Sugarcane agroindustry; Migration. Crisis.

\title{
Resumen
}

Este artículo es parte de los resultados de tesis y tiene como objetivo comprender las transformaciones socio-espaciales en la ciudad de Capinópolis (MG) debido a la territorialización de la caña de azúcar industrial Vale do Paranaíba. Con ese fin, queremos entender los efectos sociales de los trabajadores que emigran de la región noreste del municipio de Capinópolis (MG) para la actividad de corte de caña. La metodología se basa en la revisión teórica de los autores que tratan sobre el tema de la caña de azúcar y la migración, así como la investigación documental por los sitios del IBGE, SIAMIG, Prefectura de Capinópolis (MG) y la investigación de campo que nos dio la magnitud del problema aquí levantó. A continuación, las tabulaciones de datos de búsqueda se hicieron y se transforman en gráficos, tablas y fotos. Nos damos cuenta de que decenas de trabajadores perdieron sus puestos de trabajo y se vieron obligados a realizar otras actividades para sobrevivir.

Palabras clave: Capinópolis (MG); Agroindustria de lacaña de azúcar; Migración. Crisis.

\section{INTRODUÇÃO}

O presente artigo, intitulado “A cana-de-açúcar no município de Capinópolis (MG) e o (re)ordenamento socioterritorial", visa a entender o processo de expansão da agroindústria canavieira no município de Capinópolis (MG) e os desdobramentos sociais que envolvem os trabalhadores do corte de cana territorializados neste município.

A crise econômica no setor canavieiro vem afetando os trabalhadores em razão do fechamento de várias unidades espalhadas pelo território brasileiro. No município de Capinópolis (MG), este problema tem atingido centenas de trabalhadores que sobreviviam do labor no corte de cana na agroindústria canavieira Vale do Paranaíba. Hoje, eles sofrem com 
desemprego e com a consequente falta de alimentos e de condições básicas para sobrevivência.

A escolha do município de Capinópolis (MG), que integra a Microrregião Geográfica de Ituiutaba (MG), deve-se ao fato de que a agroindústria canavieira Vale do Paranaíba, pertencente ao Grupo João Lyra e instalada no município em 2003, mantém o corte manual da cana-de-açúcar, o que provoca a migração de centenas de trabalhadores oriundos da Região Nordeste para o trabalho nos canaviais, em condições precárias de trabalho, de moradia, de alimentação e de transporte, além da ocorrência de atrasos no pagamento dos salários.

A metodologia da pesquisa baseou-se na pesquisa teórica, a partir da qual reunimos, lemos e fichamos todas as bibliografias que tratam do tema e que servem de base teórica para sustentação das ideias desenvolvidas ao longo deste trabalho. $\mathrm{Na}$ pesquisa documental, procedemos o levantamento de dados de fonte secundária, realizado mediante publicações do Instituto Brasileiro de Geografia e Estatística (IBGE) (Censos Agropecuários, Produção Agrícola Municipal). As informações extraídas destas publicações são relacionadas à produção de cana ao longo da década de 1990 até o ano de 2014. Ademais, foram feitas pesquisas nos sites do IBGE, da União da Indústria de Cana-de-açúcar (ÚNICA), do Sindicato da Indústria de Fabricação do Álcool no Estado de Minas Gerais (SIAMIG), da Pastoral da Terra, da Pastoral do Migrante, do Ministério da Agricultura, do Ministério do Desenvolvimento Agrário (MDA), entre outros.

A pesquisa de campo é o instrumento necessário e indispensável para realizar investigações de quaisquer naturezas. Ao se tratar da pesquisa de campo geográfica, a sua importância é ampliada, pois é o momento no qual o pesquisador entra em contato direto com a realidade a ser estudada, interage com seus sujeitos/objetos, obtém as condições para entender como os entrevistados se percebem, inseridos em suas próprias dinâmicas de vida e trabalho, e estabelece uma análise coerente, ao diferenciar a sua percepção sobre os sujeitos.

Estruturalmente, o artigo está divido em duas partes. Na primeira, buscamos compreender o processo de implantação da agroindústria canavieira Vale do Paranaíba no município de Capinópolis (MG) e o discurso do progresso. Na segunda parte, objetivamos entender a crise econômica do Grupo João Lyra e os rebatimentos na vida dos trabalhadores que sofrem em função do desemprego e da escassez de alimentos. 


\title{
Implantação da agroindústria canavieira Vale do Paranaíba e o discurso do progresso
}

Na década de 1990, iniciou-se o processo de expansão dos grupos canavieiros nordestinos em direção ao Centro-Sul do país para implantação de novas unidades agroindustriais canavieiras, especialmente, no Triângulo Mineiro. Na corrida por novos territórios para a implantação de novas unidades produtoras de cana-de-açúcar, destacam-se os Grupos alagoanos João Lyra, Carlos Lyra e Tércio Wanderley.

Oliveira (2009) afirma que o processo de expansão do capital agroindustrial canavieiro é resultado da dinâmica da escala nacional e planetária em busca de acumulação de capital:

\begin{abstract}
Diríamos ainda que esta nova dinâmica apresentada pelo capital agroindustrial canavieiro decorre, como destacamos anteriormente, do movimento geral do capital em escala nacional e planetária, que busca por meio da racionalização da produção e do processo de trabalho novos patamares de acumulação. Nesse contexto, o processo de reestruturação produtiva e a adoção de padrões flexíveis de acumulação (a exemplo do modelo toyotista) constituem o caminho para a consolidação de sua condição enquanto "sujeito" sócio-histórico. (OLIVEIRA, 2009, p. 114).
\end{abstract}

Segundo Oliveira (2009),vários grupos alagoanos implantaram agroindústrias canavieiras no Centro-Sul, mas o Grupo João Lyra foi o primeiro a adquirir uma agroindústria da cana em Minas Gerais e expandir sua área de atuação.

\begin{abstract}
O primeiro grupo alagoano a chegar a Minas Gerais foi o João Lyra, ainda nos anos 1980. Dono de três unidades em Alagoas (Laginha, Uruba e Guaxuma) o grupo comprou naquela época a unidade Triálcool, em Canápolis/MG, a qual foi ampliada, passando a moer atualmente em média 1,3 milhões de toneladas de cana. Em 2003, o grupo inaugurou uma segunda unidade em Minas Gerais, a Vale do Paranaíba. Naquele ano (safra 2003/2004) por estar em fase de teste moeu apenas 300 mil toneladas de cana, porém possui capacidade para moer 2 milhões a 2,5 milhões de toneladas. (OLIVEIRA, 2009, p. 117, grifos da autora).
\end{abstract}

A agroindústria canavieira Laginha Agroindustrial S/A - unidade Vale do Paranaíba (foto 1), situada no município de Capinópolis (MG), no Triângulo Mineiro, foi incorporada ao Grupo João Lyra em 2003. Além da Vale do Paranaíba e da Triálcool em Minas Gerais, este Grupo possui mais três agroindústrias canavieiras no estado de Alagoas.

De acordo com o Grupo João Lyra ${ }^{1}$, a unidade agroindustrial Vale do Paranaíba foi montada com tecnologia inovadora, executando desde o plantio até o aproveitamento e a

\footnotetext{
${ }^{1}$ Grupo João Lyra. USINAS.Disponível em:<http://www.grupojl.com.br>. Acesso em: 11 ago. 2015.
} 
transformação da matéria-prima com a utilização de difusores. Esta unidade possui capacidade de 2,5 milhões de sacas anuais de cana-de-açúcar, além de produzir $110.000 \mathrm{~m}^{3}$ de álcool. A produção de 2007/2008 ficou em torno de 1,6 milhões de sacas de cana e $89.000 \mathrm{~m}^{3}$ de álcool.

\section{Foto 1 - Município de Capinópolis (MG): agroindústria Laginha S/A - Unidade Vale do Paranaíba (2016).}

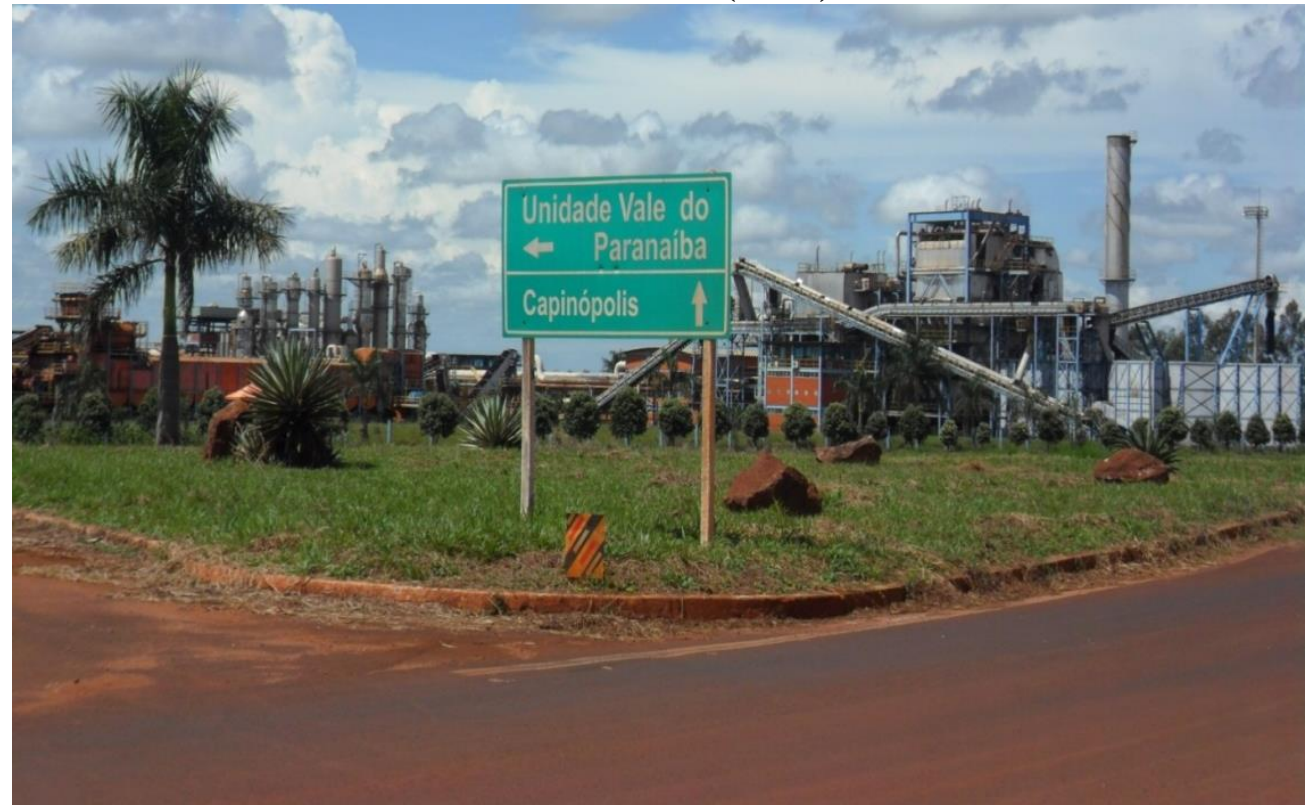

Fonte: Silva, L.C.S. (2016).

A escassez de terras em Alagoas e o desejo pela expansão dos negócios levaram o Grupo João Lyra a adquirir a agroindústria canavieira Triálcool, no município de Canápolis (MG), em 1988, e a Vale do Paranaíba, no município de Capinópolis (MG), em 2003.

O mapa 1 mostra a evolução das áreas destinadas ao cultivo da cana-de-açúcar na Microrregião Geográfica de Ituiutaba, com destaque para o município de Capinópolis (MG), no período entre 2003 e 2013. 
Mapa 1 - Microrregião Geográfica de Ituiutaba (MG): evolução da área de canade-açúcar (2003-2013).

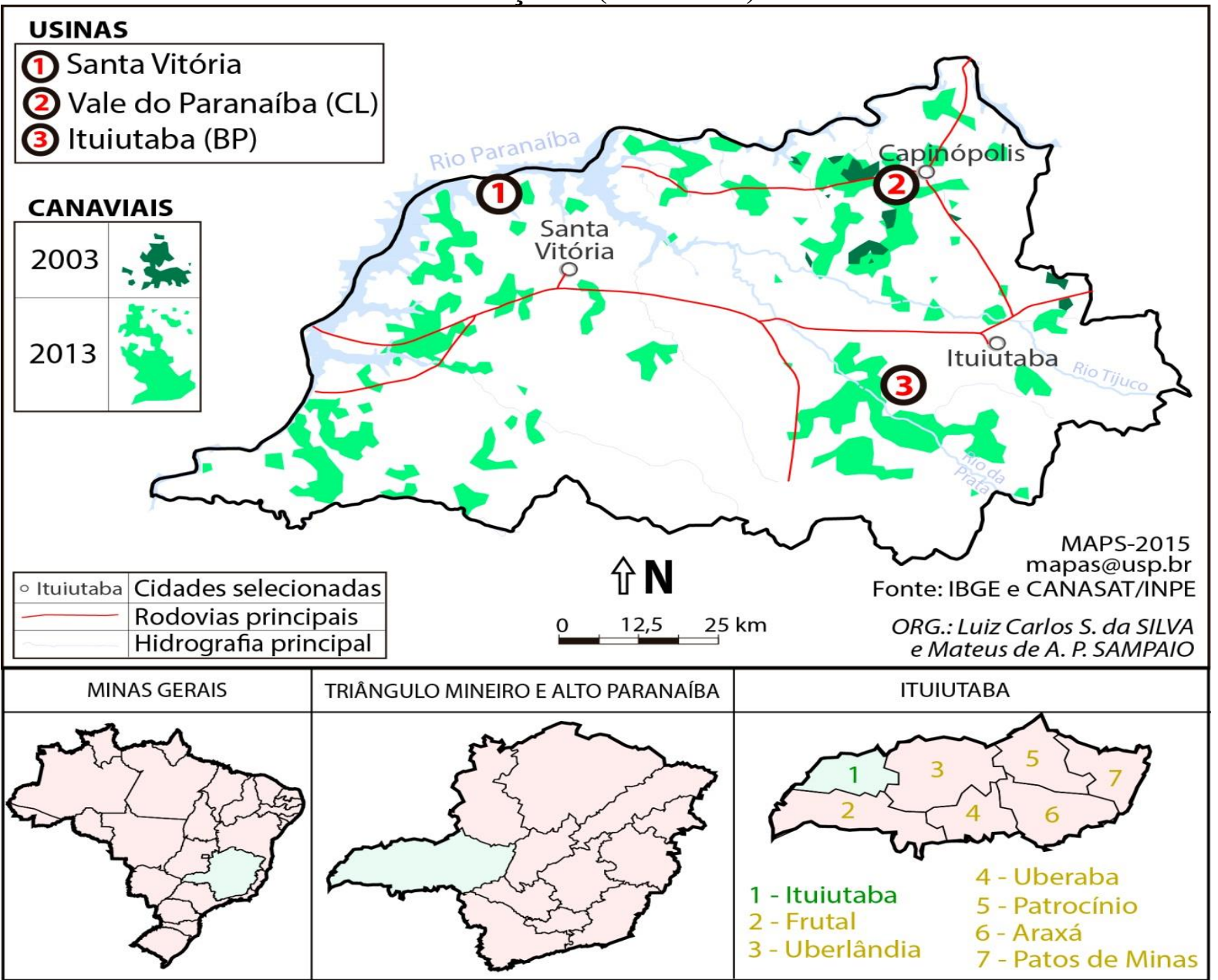

Fonte: IBGE e CANA SAT/INPE (2015) - Org.: Silva, L.C.S. (2015) - Elab: Sampaio, M. A.P. (2015).

A expansão da área de cana-de-açúcar plantada no município de Capinópolis (MG), conforme ilustra o mapa 1, evidencia uma investida do capital agroindustrial canavieiro nesta região, (re)ordenando o espaço urbano e rural pelas disputas territoriais com outras culturas existentes, como a soja e o milho.

Conquanto as culturas da soja e do milho tenham predominado no município de Capinópolis (MG), a cana-de-açúcar ganhou espaço porque se apresentou como mais lucrativa para os arrendatários. Dessa forma, a cana foi se expandindo para além dos limites do município.

Thomaz Júnior (2010, p. 05) afirma que “em relação às tantas outras formas de expressão do capital, no que tange à dinâmica, às estratégias reprodutivas, de controle do 
trabalho, e à aposta da sua constante precarização/fragilização, há semelhanças.” Ademais, o autor defende que:

É no interior dos conflitos (territoriais) que temos o fio condutor das ações dos sujeitos envolvidos nesse cenário. Então, as ações que antepõem trabalhadores $\mathrm{x}$ capital, as fissuras intercapital reveladas pela necessidade de terras planas, férteis e com disponibilidade hídrica - portanto aptas à mecanização -, e entre os próprios trabalhadores, são, por excelência, os exemplos das disputas por território que revelam o conteúdo e os significados do processo expansionista do agronegócio em geral. (THOMAZ JÚNIOR, 2010, p. 5).

No gráfico 1, é possível analisar, a partir de 2003, como a produção de cana-deaçúcar veio aumentando em relação às culturas de soja e milho na região, apesar das especificidades do segmento agroindustrial canavieiro.

Gráfico 1 - Município de Capinópolis (MG): área plantada (he) - cana-de-açúcar, milho e soja (2003-2014).

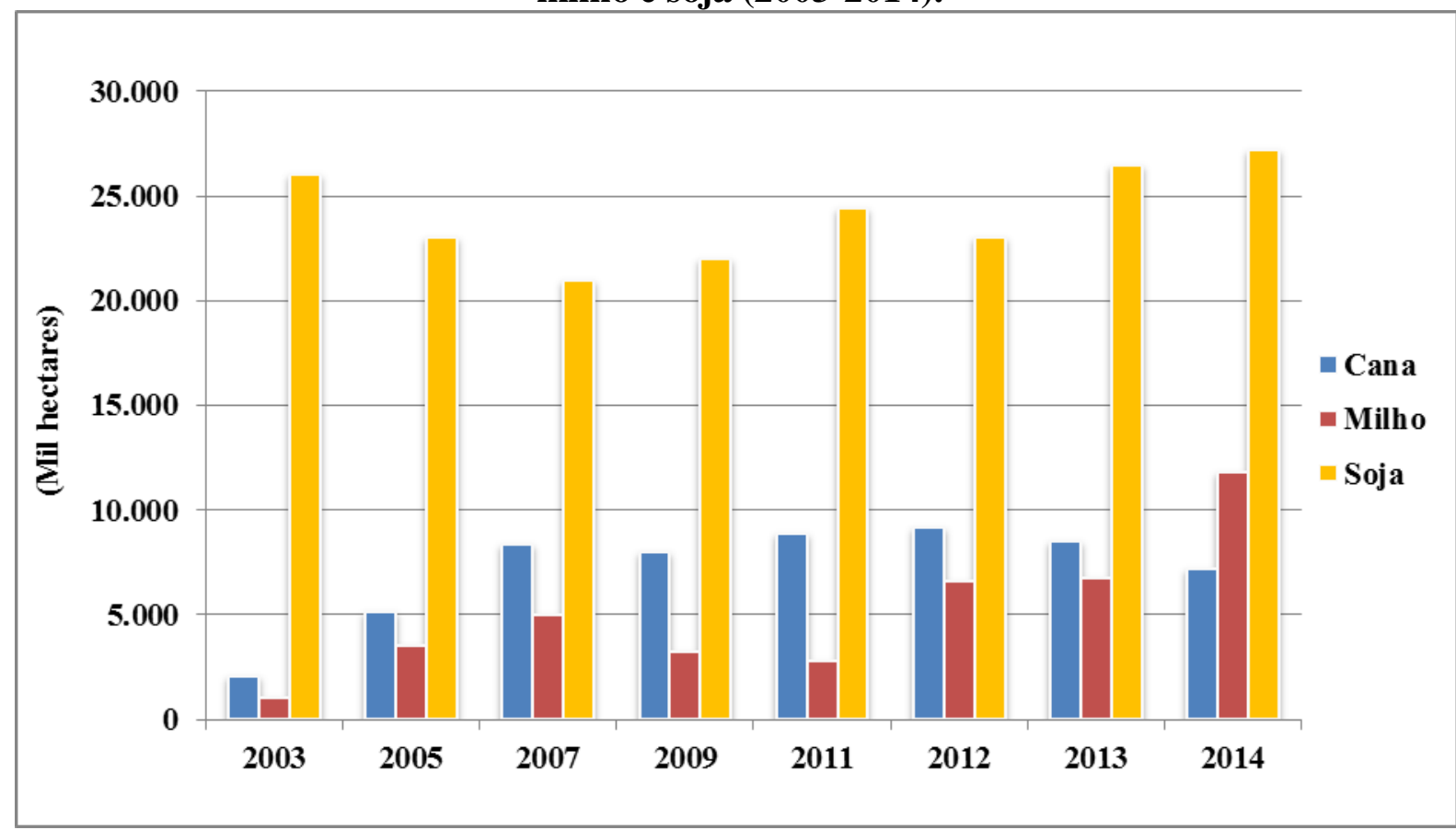

Fonte: IBGE - Produção Agrícola Municipal (2016) - Org.: Silva, L.C.S. (2015).

O gráfico 1 mostra que a área plantada de soja sempre esteve à frente da área de cana-de-açúcar. Isto demonstra que, mesmo com o avanço da cana sobre esse município, a soja e o milho sempre foram cultivadas na maior parte das terras agricultáveis do município de Capinópolis (MG). 
É possível analisar, também, que a área destinada à produção de milho sempre esteve abaixo da área de produção de cana-de-açúcar no período mencionado, superando-a somente em 2014. Segundo Oliveira (2009, p. 116), "a área plantada com cana-de-açúcar da Vale do Paranaíba compreende cerca de 21.000 mil hectares, dos quais $20 \%$ eram própria, $70 \%$ arrendada e $10 \%$ de fornecedores." Ou seja, a área plantada de cana-de-açúcar não respeitava a fronteira do município, visto que necessitava de mais terras para a sua expansão, avançando sobre os municípios vizinhos, como Canápolis (MG), Ipiaçú (MG) e Ituiutaba (MG). Na opinião de Castro (1984),

[...] a exploração da cana-de-açúcar se processa num regime de autofagia: a cana devorando tudo em torno de si, engolindo terras e mais terras, consumindo o humo do solo, aniquilando as pequenas culturas indefesas e o próprio capital humano, do qual sua cultura tira toda a vida. (CASTRO, 1984, p. 116).

Em sua investida, o capital agroindustrial canavieiro age de forma selvagem quando consome terra e capital humano, expulsando os agricultores camponeses de suas terras e (re)definindo os territórios para, dessa forma, criar as condições de perpetuação do seu domínio sobre o espaço, a água e toda riqueza ali existente.

Carvalho (2009) tece críticas ao modelo de expansão da cana-de-açúcar no Brasil quando afirma que este modelo impõe uma ruptura das formas de vida tradicionalmente construídas pelos agricultores camponeses, os verdadeiros donos da terra. O autor assevera que:

\footnotetext{
Os resultados desse processo, além das mudanças nas relações de trabalho, residiram, principalmente, na degradação e perdas das terras de pequenos agricultores, visto que os objetivos eram direcionados para a ampliação da matériaprima em extensas áreas plantadas, sendo esses pequenos agricultores postos à margem do processo. Além do crescimento das matérias-primas, outro ponto importante reside no direcionamento para o aumento da escala de produção, objetivando ampliar o capital, influenciando diretamente na concentração fundiária e na especulação de terras. (CARVALHO, 2009, p. 90).
}

Quando comparamos a produção em toneladas das culturas de cana-de-açúcar, soja e milho, constatamos a superioridade da primeira sobre as últimas, conforme se verifica no gráfico 2, abaixo.

Nota-se que a produção de cana-de-açúcar vem (re) ordenando o território em Capinópolis $(\mathrm{MG})$ para atender às demandas de etanol e açúcar do mercado nacional e internacional. 
Gráfico 2 - Município de Capinópolis (MG): produção (ton.) de cana-de-açúcar, soja e milho (2003-2014).

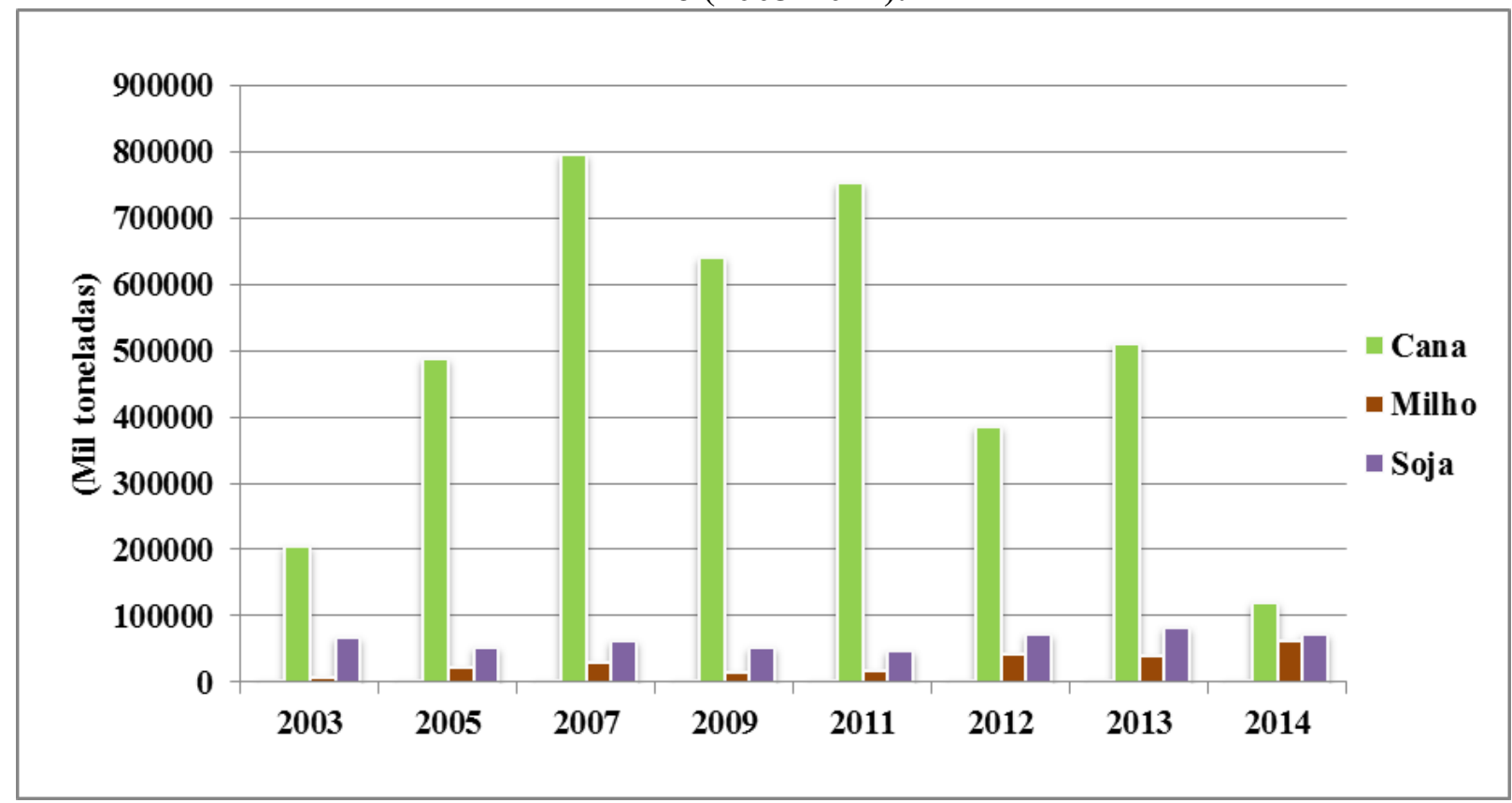

Fonte: IBGE - Produção Agrícola Municipal (2015) - Org.: Silva, L.C.S. (2016).

No gráfico 2 é possível constatar, ainda, uma queda elevada da produção de canade-açúcar no município de Capinópolis (MG) entre 2012 e 2014, como resultado da crise econômica mundial iniciada em 2008, cujos reflexos incidiram diretamente no setor canavieiro do Brasil. Esta crise, aliada à má gestão, desencadeou a falência do Grupo João Lyra e o fechamento de todas as suas agroindústrias canavieiras nos estados de Alagoas e Minas Gerais, sobretudo, da agroindústria canavieira Vale do Paranaíba (objeto da nossa pesquisa), instalada em Capinópolis (MG).

A partir da leitura do mapa 2, disposto adiante, é possível analisar o que sobrou da área plantada de cana-de-açúcar dois anos após a falência da agroindústria canavieira Vale do Paranaíba, o que reforça a queda da produção de cana, apontada, anteriormente, no gráfico 2.

A expansão da cana-de-açúcar sobre as áreas onde havia o domínio da plantação de milho, soja e sorgo começa a passar por um processo de decadência em função da crise econômica enfrentada pelo Grupo João Lyra. Conforme discutiremos na próxima seção, esta criseafetou diretamente a agroindústria canavieira Vale do Paranaíba e, por conseguinte, a vida dos trabalhadores envolvidos nessa atividade. 
Mapa 2 - Município de Capinópolis (MG): área plantada de cana-de-açúcar da Agroindústria Canavieira Vale do Paranaíba (2016).

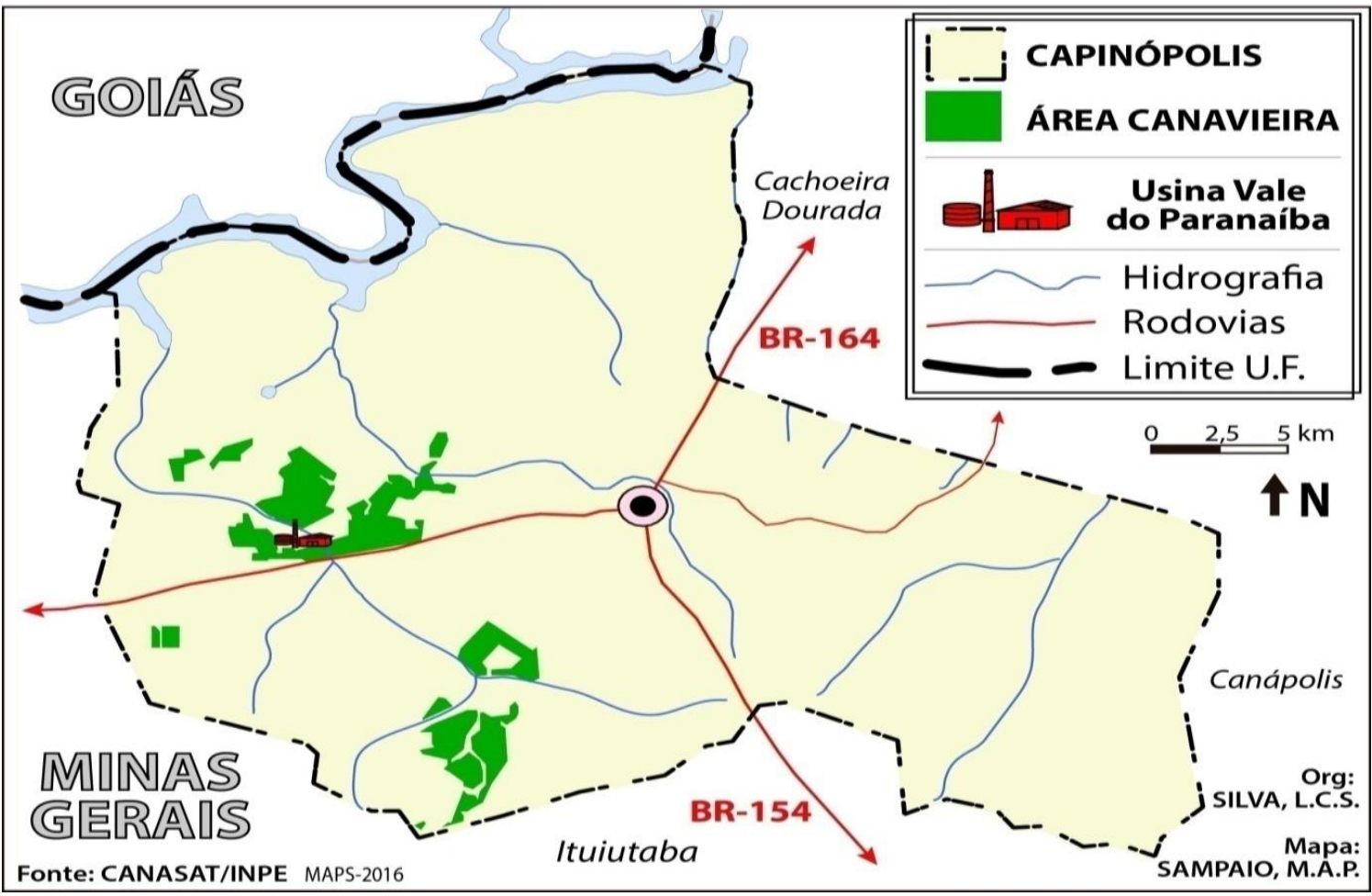

Fonte: CANASAT/INPE MAPS - 2016 - Mapa: Org.: Silva, L.C. S.(2016) - Sampaio, M.A.P. (2016).

\section{Fechamento da agroindústria Vale do Paranaíba e seus desdobramentos no trabalho}

A crise econômica mundial iniciada em 2008 trouxe sérios efeitos, especialmente, para os países emergentes que têm na produção agrícola a base de sua economia. O Brasil está inserido neste contexto como modelo de economia, por seu potencial na produção agrícola, principalmente, de soja, de milho e de cana-de-açúcar para a produção de etanol e açúcar. A cana tem sido a cultura mais afetada com a crise mundial iniciada em 2008, pois a maior parte da produção de açúcar e etanol era destinada à exportação.

Com a citada crise, a demanda pelo etanol e pelo açúcar diminuiu, o que desencadeou um processo de falência de dezenas de agroindústrias canavieiras, mormente, daquelas que já apresentavam alguma dificuldade financeira ou que estavam em recuperação judicial $^{2}$. Neste último caso se enquadra o Grupo João Lyra, que recorreu à Justiça com um

\footnotetext{
${ }^{2}$ Possibilidade de reestruturação das empresas economicamente viáveis que passem por dificuldades momentâneas, mantendo os empregos e os pagamentos aos credores. Um dos grandes méritos apontados nessa legislação falimentar é a prioridade dada à manutenção da empresa e dos seus recursos produtivos. Ao acabar com a concordata e criar as figuras da recuperação judicial e extrajudicial, a nova lei aumenta a abrangência e a
} 
pedido de recuperação judicial em novembro de 2008. Iniciava-se, então, o processo de falência de um dos maiores grupos canavieiros do nordeste do país.

Consoante o jornal eletrônico Correio de Uberlândia ${ }^{3}$ (2014), o Tribunal de Justiça de Alagoas (TJ-AL) decretou a falência do Grupo João Lyra, formado por cinco usinas de beneficiamento de cana-de-açúcar neste estado e em Minas Gerais. Convém acrescentar que, no processo, ainda cabe recurso e que o Grupo é de propriedade do deputado João Lyra (PSD-AL).

As duas usinas nos municípios mineiros estão em Capinópolis e Canápolis. Atualmente, ambas estão paradas em virtude da entressafra. Porém, de acordo com as lideranças sindicalistas nas localidades, a decisão judicial, pelo menos por enquanto, não muda a situação vivida pelos trabalhadores, ainda que muitos ainda cobrem salários atrasados das empresas. Os sindicatos não informaram quantas pessoas estão sem receber.

O município de Capinópolis (MG) vem passando por sérias dificuldades financeiras. Segundo a sua prefeita, Dinair Isaac, “centenas de trabalhadores perderam seus empregos e não receberam seus salários colocando suas famílias em estado de desespero porque não têm como sobreviver na cidade com a usina fechada". (informação verbal, 2016).

Enquanto se trava uma batalha judicial com 276 ações na Justiça do trabalho de Ituiutaba (MG), a agroindústria canavieira Vale do Paranaíba está completamente abandonada (foto 2). Conforme o Sindicato dos Trabalhadores Rurais de Capinópolis (MG), a maioria dessas ações é trabalhista e movida pelo sindicato, de forma tanto coletiva quanto individual, para que os sujeitos recebam seus direitos trabalhistas, como rescisão contratual, Fundo de Garantia por Tempo de Serviço (FGTS) e o Seguro Desemprego.

De acordo com o Jornal eletrônico Tudo em Dia ${ }^{4}$, “a Prefeita de Capinópolis, Dinair, que já se reuniu com o Ministério Público há alguns meses (2015), tem se mostrado preocupada com o que vem ocorrendo, não só com os produtores rurais prejudicados, como

flexibilidade nos processos de recuperação de empresas, mediante o desenho de alternativas para o enfrentamento das dificuldades econômicas e financeiras da empresa devedora. Disponível em: <http://www.jusbrasil.com.br/topicos/297012/recuperacao-judicial>. Acesso em: maio 2016.

${ }^{3}$ Disponível em: <http://www.correiodeuberlandia.com.br/cidade-e-regiao/tj-al-decreta-falencia-do-grupo-joaolyra-que-tem-2-usinas-no-triangulo/>. Acesso em: jun. 2016.

${ }^{4}$ Disponível em: <http://www.tudoemdia.com/2014/08/dinair-isaac-recebe-dirigentes-da-massa-falida-grupojoao-lyra $\geq$. Acesso em: maio de 2016. 
também com os trabalhadores, e a influência negativa que a situação tem trazido para o comércio local, além dos fornecedores que têm muito dinheiro para receber". A prefeita argumenta ainda que "[...] não é somente o valor econômico que as usinas representam para a região, mas o seu fechamento provocou o desemprego para centenas de famílias, que estão nos municípios da região".

\section{Foto 2 - Município de Capinópolis (MG): abandono da agroindústria canavieira Vale do} Paranaíba (2016).

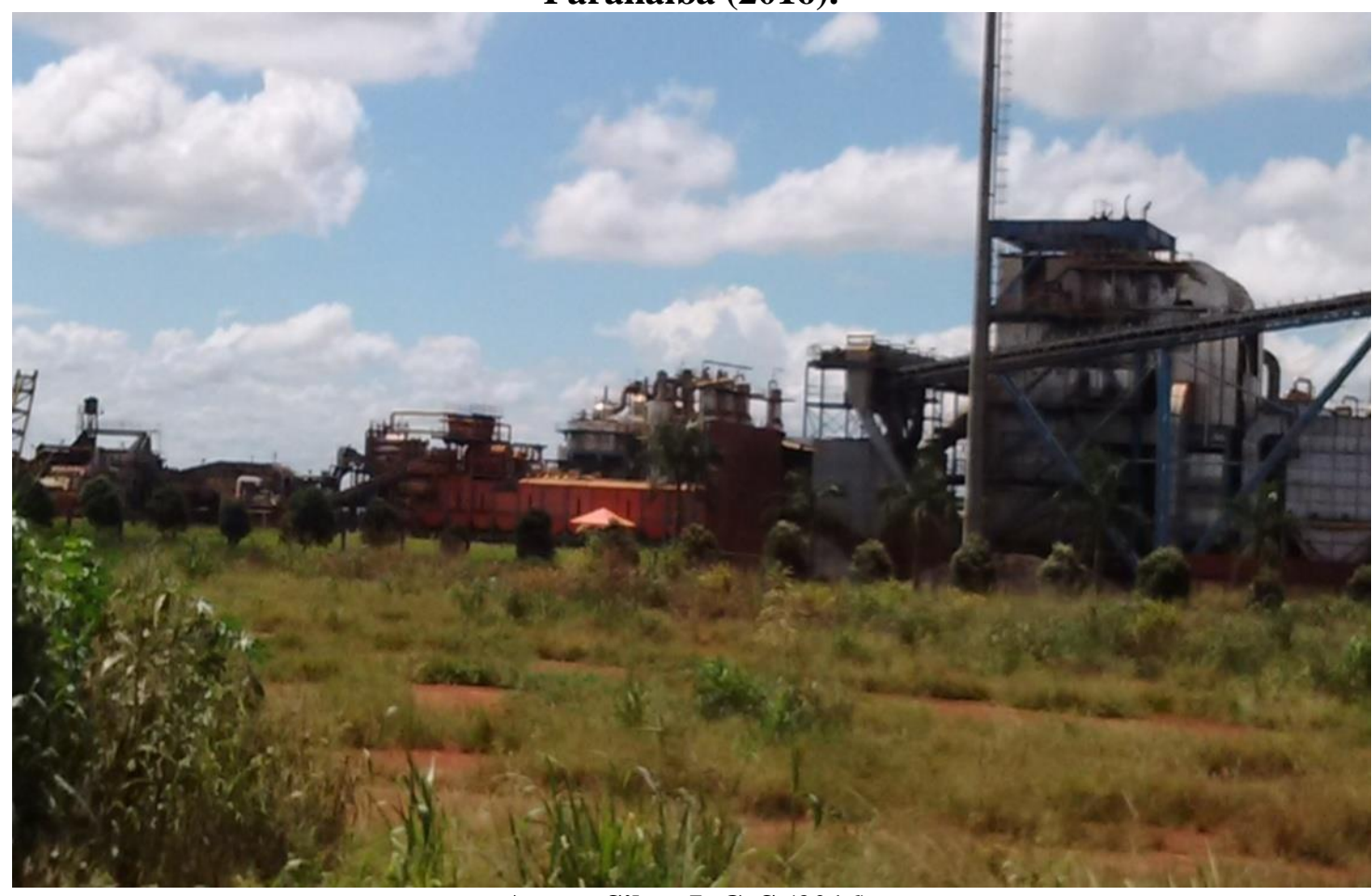

Autor: Silva, L.C. S (2016).

À procura por trabalhadores da agroindústria canavieira Vale do Paranaíba, na pesquisa de campo realizada entre janeiro e fevereiro de 2016, visitamos vários bairros da cidade de Capinópolis (MG) para coletar dados que permitissem entender os desdobramentos sociais da falência desta agroindústria na vida desses trabalhadores que ainda residem na cidade. Nas entrevistas realizadas com eles, foi possível constatar que $25 \%$ desses trabalhadores estão desempregados e $75 \%$ desempenhando outras atividades temporárias, como a de despendoador de milho ${ }^{5}$. Na opinião do Sr. José Remo Oliones Nogueira, que

\footnotetext{
${ }^{5}$ É o profissional que remove os pendões dos pés de milho antes de estarem prontos para polinizar a seda. O propósito do despendoamento é fazer a polinização cruzada, formando sementes de milho híbridas. Disponível em:< http://www.ehow.com.br/pendoes-milho-fatos_66766_. Acesso em: maio de 2016.
} 
desenvolve esta atividade de despendoador de milho na Monsanto ${ }^{6}$, "esse tipo de trabalho é temporário com duração média de seis meses.” (Informação verbal, 2016).

A partir dessa realidade vivida pelos trabalhadores, percebemos uma fragmentação do trabalho que desencadeia uma (des)realização do trabalho em função da redefinição de profissões e qualificações exigidas aos trabalhadores, bem como de readaptações e sujeições a diferentes tipos de trabalho ainda mais precários.

Thomaz Júnior (2012) avalia esta problemática e defende a seguinte tese:

Quando nos ocupamos com (des)realização e as novas identidades do trabalho territorialmente expressas na plasticidade que se refaz continuamente, estamos preocupados com os desdobramentos para os trabalhadores da constante redefinição de profissões, habilitações, inserções autônomas etc., entremeada, em vários casos, com experiências de despossessão. Essa trajetória de fragmentações atinge em cheio o trabalho, e são essas as evidências mais profundas do estranhamento que acrescentam desafios à compreensão do trabalho, na perspectiva de classe. (THOMAZ JÚNIOR, 2012, p. 12).

Assim como o corte de cana-de-açúcar nas agroindústrias canavieiras, o trabalho de despendoador de milho é um trabalho que exige muito esforço físico do trabalhador, que é pago por produção (foto 3). Dessa forma, o trabalhador se vê desprotegido e se submete a trabalhos extremamente precários, insalubres e mal remunerados, em condição análoga à escravidão. As promessas de altos ganhos nos canaviais se transformam em um pesadelo para esses trabalhadores, integrantes da classe social que vive do trabalho e que dele depende para a sua existência social.

Antunes e Alves (2004), ao discutir a classe que vive do trabalho, afirma que,

Compreender, portanto, a classe-que-vive-do-trabalho, a classe trabalhadora hoje, de modo ampliado, implica entender este conjunto de seres sociais que vivem da venda da sua força de trabalho, que são assalariados e desprovidos dos meios de produção. Como todo trabalho produtivo é assalariado, mas nem todo trabalhador assalariado é produtivo, uma noção contemporânea de classe trabalhadora deve incorporar a totalidade dos(as) trabalhadores(as) assalariados(as). (ANTUNES; ALVES, 2004, p. 9).

\footnotetext{
${ }^{6}$ A Companhia Monsanto é uma empresa multinacional de agricultura e biotecnologia. Sediada nos Estados Unidos, é a líder mundial na produção do herbicidaglifosato, vendido sob a marca Roundup. Também é, de longe, o produtor líder de sementes geneticamente modificadas (transgênicos), respondendo por $70 \%$ a $100 \%$ do market share para variadas culturas. Disponível em: 〈https://pt.wikipedia.org/wiki/Monsanto_(empresa)之. Acesso em: maio de 2016.
} 
Foto 3 - Despendoadores de milho no Estado de Goiás (2015).

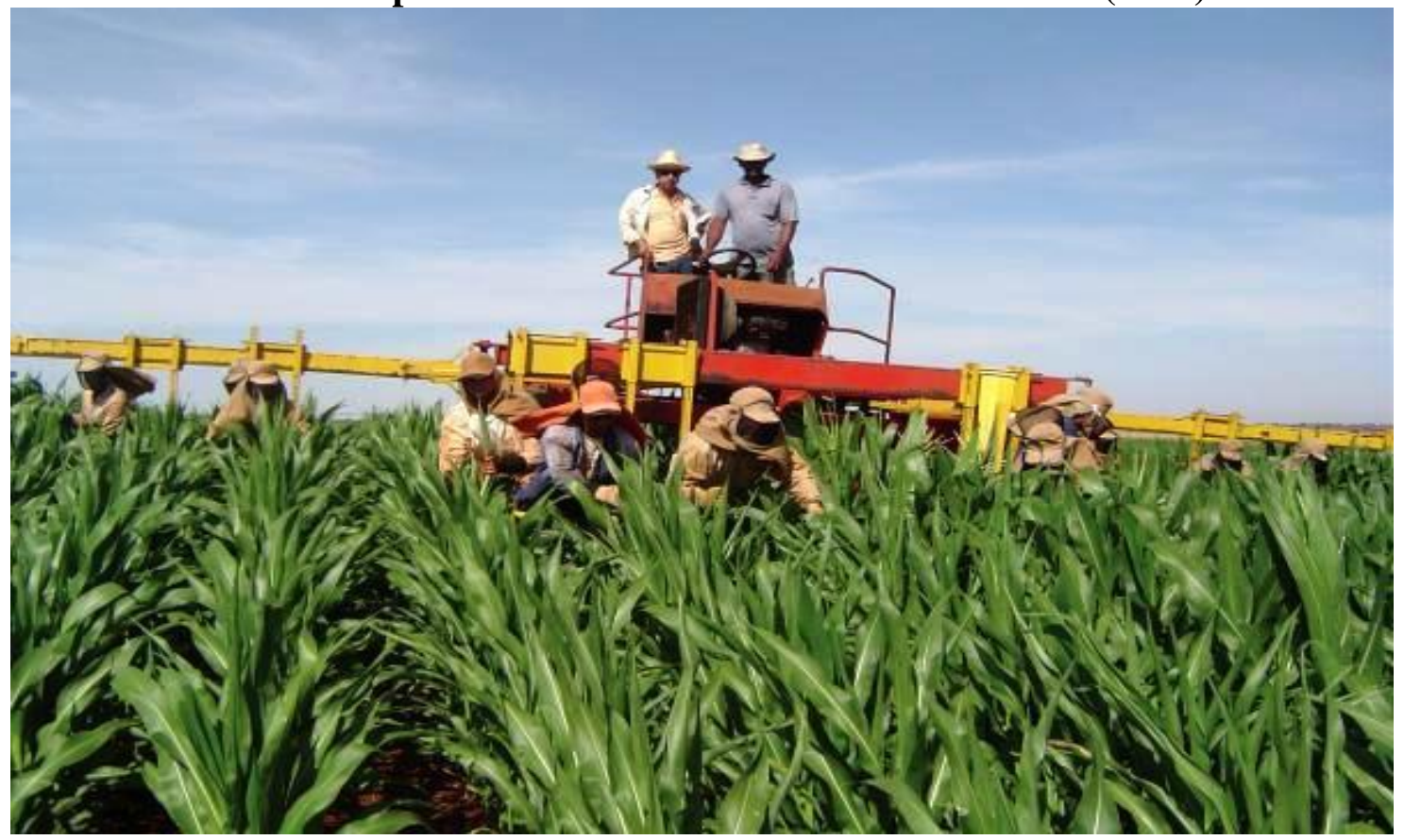

Fonte: Agrolink.com.br - Acesso em: maio 2016 - Org.: Silva, L.C.S. (2016).

Os autores Antunes e Aves (2004) reforçam que a alienação/o estranhamento é ainda mais intensa/intenso nos estratos precarizados da força humana de trabalho, que vivenciam as condições mais desprovidas de direitos e em condições de instabilidade cotidiana, dadas pelo trabalho part-time, temporário e precarizado.

O gráfico 3 mostra que, no período da pesquisa de campo, $75 \%$ dos entrevistados estavam desenvolvendo a atividade de despendoador de milho, enquanto $25 \%$ permaneciam desempregados.

O gráfico 3 indica a dramática realidade que os poucos trabalhadores migrantes que insistiram em permanecer na cidade de Capinópolis (MG)estão vivendo, posto que a única forma de sobrevivência para estes trabalhadores sustentarem a si e a sua família é o trabalho nos despendoamento de milho. Conforme Mendonça (2004),

Pensar geograficamente a relação metabólica entre o homem e a natureza e suas configurações sócio-territoriais significa perceber uma nova sociabilidade construída a partir da relação capital $\mathrm{x}$ trabalho. A reestruturação produtiva do capital processada nos últimos 20 anos do século $\mathrm{XX}$, portadora de novas formas de produção e de trabalho resultou em alterações profundas no processo de acumulação e (re)produção de capitais e em uma verdadeira metamorfose nas relações de trabalho, com conseqüências danosas para os trabalhadores, bem como para os movimentos sindical e operário, e para a classe trabalhadora de forma geral. (MENDONÇA, 2004, p. 1). 


\section{Gráfico 3 - Município de Capinópolis (MG): ocupação atual dos ex-cortadores da} agroindústria canavieira Vale do Paranaíba (2016).

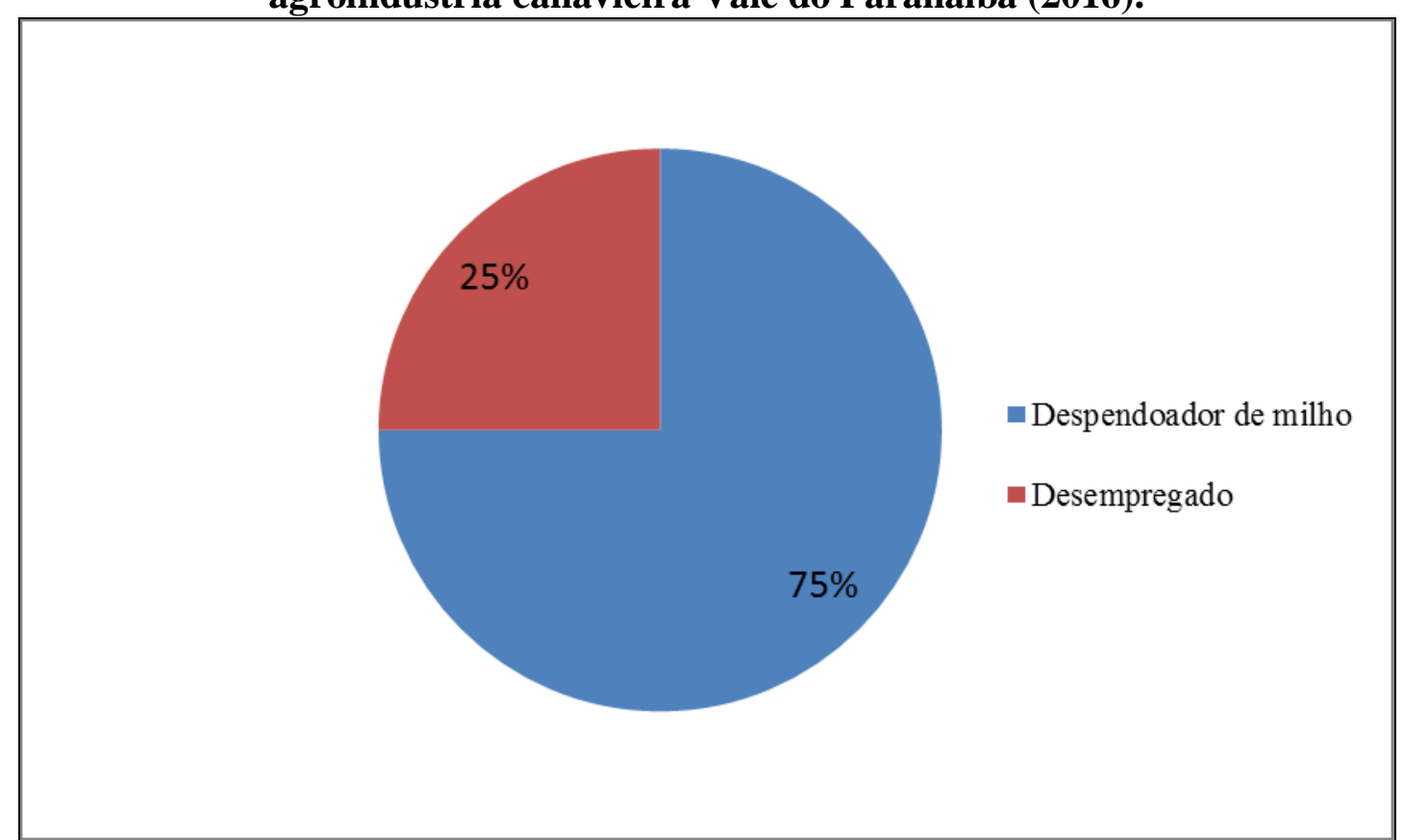

Fonte: Pesquisa de campo (2016) - Org.: Silva, L.C.S. (2016).

Nessa lógica da relação metabólica entre capital e trabalho, todas as consequências da crise do capital recaem sobre o trabalhador, o qual é descartado, tendo que sobreviver do subemprego na forma mais precária possível. Diante disso, é preciso construir políticas públicas que consigam oferecer trabalho e dignidade aos trabalhadores que sofrem com o desemprego causado pelo fechamento dessas agroindústrias canavieiras.

\section{CONSIDERAÇÕES FINAIS}

A territorialização da agroindústria Vale do Paranaíba no município de Capinópolis (MG), em 2003, trouxe mudanças na relação campo e cidade. Novas formas de produção dos espaços rural e urbano se impuseram a partir do domínio do capital agroindustrial canavieiro liderado pelo Grupo alagoano João Lyra.

A geração de emprego foi um fator de grande importância econômica e social para o pequeno município de Capinópolis (MG), uma vez que alimentou a esperança de que a cidade entraria em um novo ciclo de desenvolvimento social e econômico, patrocinado pela expansão da agroindústria canavieira na região. Com isso, centenas de trabalhadores 
migraram para o município em busca do trabalho ofertado pela agroindústria canavieira Vale do Paranaíba.

Com a instalação da agroindústria, além da geração de empregos para a população da cidade, ocorre o aumento da arrecadação de impostos. Nesse contexto, havia uma euforia muito grande na cidade, que, até então, era desconhecida no cenário regional e nacional e, entre 2003 e 2011, despontou como um dos municípios produtores de cana-de-açúcar da região.

A agroindústria canavieira que, até certo momento, era motivo de orgulho para os políticos e para a população capinopolense, começa a ser questionada quando os seus efeitos negativos foram percebidos. Dentre estes, salientam-se as queimadas no período de safra, que ocasionam problemas respiratórios em razão da fuligem gerada pela queima da cana para a colheita.

A relação capital $\mathrm{x}$ trabalho se tensionou ainda mais quando o Grupo João Lyra entrou em processo de falência, em 2014, resultado da crise mundial iniciada nos Estados Unidos, em 2008, aliada à má gestão do Grupo. Tal situação se refletiu negativamente sobre o município e a população que dependia dos empregos gerados pela agroindústria canavieira Vale do Paranaíba.

A falência do Grupo João Lyra teve desdobramentos negativos, sobretudo, na vida dos trabalhadores migrantes, porquanto estes perderam seus empregos e foram forçados a migrar novamente para outras regiões canavieiras em busca de trabalho para sua sobrevivência e de sua família. Portanto, tornaram-se vítimas do poder destrutivo do capital que se apropria da força de trabalho e a descarta quando esta não mais lhe serve.

\section{REFERÊNCIAS}

ALVES, G. A. P.; ANTUNES, R. As mutações no mundo do trabalho na era da mundialização do capital. Educação e Sociedade, Campinas, v. 25, n. 87, p. 335-351, 2004.

CARVALHO, H. M. Impactos econômicos, sociais e ambientais devido à expansão da oferta do etanol no Brasil.2007. Disponível em:<www.landaction.org/spip/spip.php? article190>. Acesso em: 29 jun. 2013.

CASTRO, J. Geografia da fome. O dilema brasileiro: pão ou aço. Rio de Janeiro: Edições Antares, 1984. 348 p. 


\section{CONCEIÇÃO, A. L. ESTADO, CAPITAL E A FARSA DA EXPANSÃO DO}

AGRONEGÓCIO. Meridiano - Revista de Geografía, v. 01, p. 81-104, 2013.

\section{INSTITUTO BRASILEIRO DE GEOGRAFIA E ESTATÍSTICA (IBGE). Produção}

Agrícola Municipal: 1990-2001. Disponível em:

<http://www.sidra.ibge.gov.br/bda/tabela/protabl.asp?>. Acesso em: 22 abr. de 2015.

INSTITUTO BRASILEIRO DE GEOGRAFIA E ESTATÍSTICA (IBGE). Produção Agrícola Municipal: 2001-2013. Disponível em:

<http://www.sidra.ibge.gov.br/bda/tabela/protabl.asp?>. Acesso em: 22 abr. 2015.

MENDONÇA, M. L.; PITTA T. F.; XAVIER, V. C. A agroindústria canavieira e a crise econômica mundial.São Paulo: Outras Expressões, 2012. v. 1.

OLIVEIRA, A. M. S. Reordenamento territorial e produtivo do agronegócio canavieiro no Brasil e os desdobramentos para o trabalho. 2009. $586 \mathrm{f}$. Tese (Doutorado em Geografia) FCT - UNESP, 2009, Presidente Prudente, 2009.

THOMAZ JR, A. Por trás dos canaviais os nós da cana: a relação capital-trabalho e o movimento sindical. São Paulo: Annablume/FAPESP, 2002. 388 p.

. Por uma geografia do trabalho. Pegada (UNESP. Impresso), Presidente Prudente, v. esp., n. especial, p. 4-26, 2002.

Gestão e ordenamento territorial da relação capital-trabalho na agroindústria canavieira Brasil. Revista Pegada Eletrônica (Online), v. 11, p. 3-33, 2010.

Movimento sindical e práxis política na agroindústria sucro-alcooleira. ScriptaNova (Barcelona), Barcelona, v. 5, n.5, p. 1-10, 1997.

. Os desafios para o movimento sindical no cenário de (re)definições do capital e reformas jurídico-institucionais causas das mudanças climáticas na terra. Ciência Geográfica, v. 3, n.7, p. 10-14, 1997.

\section{Autores}

Luiz Carlos Santos da Silva - Possui Graduação em Geografia pela Universidade Federal de Uberlândia (UFU) e Mestrado em Geografia pela Universidade Federal de Goiás (UFG). Atualmente é professor da Educação Básica da Rede Estadual de Minas Gerais.

Estevane de Paula Pontes Mendes - Possui Graduação em Geografia pela Universidade Federal de Goiás (UFG), Mestrado em Geografia pela Universidade Federal de Uberlândia (UFU) e Doutorado em Geografia pela Universidade Estadual Paulista Júlio de Mesquita Filho (UNESP). Atualmente é Professora pela Universidade Federal de Goiás (UFG), Campus de Catalão. 
SILVA, L. C. S; MENDES, E. P. P.

A cana-de-açúcar no município de Capinópolis (MG) e o (re)ordenamento socioterritorial

Artigo recebido em: 18 de setembro de 2016.

Artigo aceito em: 15 de dezembro de 2016. 